\title{
Do Audit Committees Have Capacity to Monitor Management: The Case of Serbia
}

\author{
Savka VUČKOVIĆ-MILUTINOVIĆ ${ }^{1}$
}

\begin{abstract}
In this paper we examine audit committees composition and work in companies in Serbia. Audit committees are seen as integral part of the modern system of corporate governance worldwide which role is even reinforced with new EU Auditing Directive. According to the agency theory, this committee shell contribute to the prevention of management opportunistic behaviour by performing set of monitoring activities. In this study, we intend to illuminate actual capabilities of audit committees in Serbia. We perform content analysis to assess transparency of companies with regard to audit committees and formal assumptions for the design and work of audit committees. In addition, we conduct a survey of external auditors to uncover substance of the audit committee performance. Our results show that the current state of the audit committee in Serbia is not satisfactory. We find that the level of audit committee disclosure is low, formal standards for audit committee composition and responsibilities are not fully in line with EU regulation and audit committee substance is fairly missed. Management is not effectively monitored by audit committee and it still has more power than audit committee in the process of selection of the external auditor. This paper contributes to the discussion about audit committee effectiveness with focus on an emerging country where audit committee does not have long tradition. Our findings reveal that Serbian companies have to make significant improvements in order to have audit committees able to perform substantial monitoring.
\end{abstract}

KEYWORDS: audit committee, corporate governance, institutional theory, Serbia

JEL CLASSIFICATION: M42, M48.

\section{INTRODUCTION}

New legislation on statutory audits of annual accounts was enacted in EU in 2014, with the ultimate goal of enhancing the quality of external auditing. It was provoked by the necessity of restoring investor confidence in the external auditing which was seriously undermined by the latest financial crisis and a numerous corporate scandals. The new regulation is based on more rigorous approach to auditor independence, requires tighter public oversight of external audit and introduces enhanced auditor report. Over and more, the new EU Auditing Directive (Directive 2014/56/EU) shed a new light on the role of the audit committee (AC) in ensuring a quality audit. Although the previous EU Auditing Directive (Directive 2006/43/EC) also required $\mathrm{AC}$ establishment for public interest entities (PIE) and prescribed AC monitoring responsibilities, the new Directive recognizes $\mathrm{AC}$ as one with "decisive role" in providing highquality audit. However, achievements of AC could not be taken for granted. It might easily happen that form dominates over substance meaning that AC plays just ceremonial role instead of providing effective corporate oversight. In this case, $\mathrm{AC}$ would not be only a burden for the company, but it could also lead to wrong perception of investors about the quality of companies financial statements. AC has potential to be "one of the most reliable guardians of the public

\footnotetext{
${ }^{1}$ University of Belgrade Faculty of Economics, Republic of Serbia, e-mail: saska@ekof.bg.ac.rs
} 
interest" (Levit, 2000), but benefits of AC depend of its characteristics where independence, competence and diligence are the most precious ones.

At its beginning, AC was voluntary and market-driven initiative. A lot of corporate failures accompanied by fraudulent financial reporting gave impetus for the constitution of $\mathrm{AC}$ as a special committee of the board of directors devoted to protect integrity of financial reporting process including auditing of financial statements. The benefits of ACs in terms of enhancing corporate governance have been recognized by companies as well as by regulators and lawmakers leading to a growing acceptance of ACs, which become nowadays a common structure in public interest entities all over the world. In the last three decades many countries have made ACs mandatory, at least for listing companies. However, by this time the experience with ACs had also revealed that establishing ACs had not been sufficient to provide enhanced oversight if its composition and work had not been based on sound standards. It seems clear that today the crucial question related to ACs "is not whether ACs should be established, but how to design an effective and efficient AC" (Böhm at al., 2013). Many professional associations and regulators have already attempted to formulate the best practices for ACs and academic researchers have also contributed to these efforts by looking for key inputs for effective ACs. Despite all mobilized efforts it is evident that substantial variation exists in AC practices and quite often many kinds of deficiencies are present (Beasley at al., 2009; Cohen et. al, 2010). Unsurprisingly, in many well-known corporate scandals ACs have also been part of the problem. Discussion of the effectiveness of AC is again provoked and gives stimulus for new and up-to-date research on the actual performance of ACs in practice as well as finding ways to improve it.

The issue of $\mathrm{AC}$ is not only important in developed countries where this governance structure is more or less present in last decades, but even more in emerging markets where the principal impetus for the formation of ACs was legal requirement rather than perceived value of ACs. In such environment it could easily happen that companies comply in form with regulations that relate to ACs but do not actually support ACs to exercise its duties. In that way the potential of ACs as important monitoring mechanism remains unexploited. Given the fact that in these countries the quality of financial statements as well as the quality of audit are big issues, it would be opportunely to use all possible ways to make things better, and strengthening the capacity and position of ACs is a promising one, and one which could contribute to the creation of a reliable system of financial reporting.

Despite the relevance of the AC performance issue, there has been a lack of scientific studies that have explored it in emerging economies. To date, such a study has not been conducted in Serbia. In this paper we intend to illuminate the current state of ACs in Serbia by using two avenues for research. Due to the important role that appropriate legislation could play in strengthening conditions for effective work of AC, firstly we examine the Serbian normative framework related to $\mathrm{AC}$, focusing especially on its compliance with the EU regulation. We also investigate companies' practices in implementing requirements imposed by law. These requirements are mostly in form of minimum standards so companies may choose to apply more stringent rules or just to follow the prescribed minimum. The formal legitimacy does not, however, necessarily indicate that ACs truly fulfil their duties in practice. Therefore, in addition to the examination of formal aspects of ACs work, we undertake qualitative research on actual ACs activities. In order to get competent and independent evaluation of ACs practices, this paper focuses on the experiences of external auditors. This paper is organised as follows. The next section provides the theoretical foundation and a literature review regarding the $\mathrm{AC}$ role in providing higher quality of financial reporting and auditing. The research questions of this 
study are developed in section 3, while research methodology is elaborated in section 4. A subsequent section presents the study results, followed by analysis and discussion. Finally, the concluding section highlights the most important remarks of the study.

\section{THEORETICAL BACKGROUND AND LITERATURE REVIEW}

There has been a growing interest in AC in the last few decades, but in fact it is not a new part of corporate governance structure since evidence of AC formation dates back to the 1870s. Tricker (1978) has demonstrated that in this early period ACs already existed in UK. He has also provided insight into the report of Great Western Railway's AC dated 1872, making it clear that from its beginning $\mathrm{AC}$ has had serious responsibilities related to external auditors - from communication to oversight and selection. Nevertheless, in the next 100 years ACs did not become a widespread practice in corporations and only limited public support towards the creation of AC appeared. The rise of ACs has actually begun in 1970s and was triggered by companies' collapses which made obvious the urgent need for improving corporate governance (Porter \& Gendall, 1993). Although just a few countries (e.g., Canada, Singapore) promptly imposed legal requirement for public companies to have an $\mathrm{AC}$, many other countries also experienced increase in the use of ACs. In US, where AC remained voluntary, the proportion of big public companies that established AC rose from 32\% in 1970 to $87 \%$ in 1976 (Mautz and Neumann, 1970; Mautz and Neumann, 1977). Strong encouragement by many professional associations, regulatory bodies and other initiatives which required or recommended the forming of ACs, also contributed to broader acceptance of ACs (Vanasco, 1994). Since 1978, the establishment of AC has become a listing requirement on the New York Stock Exchange, and on the American Stock Exchange since 1980. Finally, Sarbanes-Oxley Act (SOX) has made AC mandatory for listed companies in US.

The similar process of AC affirmation took place in Europe, but with some time lag. In the early 1990s ACs become prominent in UK and, somewhat later, the use of ACs started to rise in continental Europe. Köhler (2005) pointed that the dissemination of ACs in Germany increased with time and by $200385 \%$ of companies quoted in the DAX and MDAX established AC. Collier \& Zaman (2005) found that by 2003 the formation of ACs had been widely recommended by the corporate governance codes of European countries. Although not legally binding, these codes influenced on companies' practices to form ACs.

For EU countries additional incentive for the forming of ACs came from the European Commission (EC) which in 2003 announced an action plan aimed to enhance corporate governance in EU (EC, 2003). It suggested that despite a diversity of approaches among member states "some specific rules and principles need to be agreed at EU level". It recognised the need for $\mathrm{AC}$ as an essential committee of the board of directors and emphasized its role in supervising the audit function. Since this plan was welcomed, the EC issued a set of recommendations which deals, among other, with AC by promoting its formation as well as rules related to its composition, role, and operation (EC, 2005). These recommendations were, however, by its nature non-binding.

Finally in 2006 AC became mandatory for all PIE in EU. This requirement was set out in the amended Directive on statutory audits, which also established some minimum standards on AC design and scope of the work (Directive 2006/43/EC). This Directive was prompted by corporate scandals such as Parmalat, Uhold and others which seriously questioned the quality of auditing. One of the key areas addressed by the new Directive was AC. The Directive stressed 
the role of $\mathrm{AC}$ as a monitoring mechanism as well as its role in the appointment of the statutory auditor.

Not long after, another auditing reform was necessary. The investors' confidence in the reports of statutory auditors was seriously undermined by recent financial crises and numerous corporate failures that were often preceded by unqualified audit opinion. Sikka (2009) points out "markets do not seem to have been assured by unqualified audit opinion". EC reacted by proposing changes in the legislative framework, which included setting more stringent standards for performing statutory audit. In 2014 the new Directive on statutory audits was entered into force and $\mathrm{AC}$ has become even more important. The responsibilities of $\mathrm{AC}$ are prescribed more precisely now and requirements for memberships in $\mathrm{AC}$ are reinforced in order to rise the capacity of AC in discharging its responsibilities. All members of AC must be nonexecutive and the majority of them must be independent.

Expectations from $\mathrm{AC}$ are high and based on the agency theory and consideration of the $\mathrm{AC}$ as an effective monitoring mechanism. On the other hand, it becomes obvious that ACs do not always meet their duties. In the landmark case of Holinger, AC "failed to ask questions, failed to be sceptical...", and consequently did not perform effective oversight missing the fraud (Paris et al., 2004). Many empirical studies also reveal that there is gap between actual performance of ACs and their proclaimed duties (Kalbers \& Fogarty, 1998; Beasley at al., 2009; Cohen et. al, 2010). The explanation for this gap is found in institutional theory, which in contrast to agency theory indicates that companies could use control structures as "symbolic displays of conformity and social accountability to social expectations that have only a remote connection to the actual effectiveness of controls" (Kalbers \& Fogarty, 1998). Following institutional theory, AC could dominantly have a ceremonial role without making expected contribution to the monitoring efforts.

Empirical evidences are mixed suggesting that both theories - agency and institutional are useful in explaining the formation and activity of AC (Turley \& Zaman, 2004). This illuminates importance of improving capacity of AC to accomplish actual monitoring instead of playing a symbolic and passive role. Creating effective $\mathrm{AC}$ is a demanding process calling for a number conditions to be met. AC effectiveness could be best described as "multidimensional construct" (Beattie et. al, 2014). The KPMG AC Institute recognizes four dimensions in AC cycle: membership - the right people; development - induction and continuing education; policies, processes and procedures; and evaluation - continual improvement, that are crucial in achieving effective AC (KPMG, 2017). In academic literature, much of the research was directed to explore contribution of some externally observed attributes of AC (e. g. independence, expertise, number of meeting) to AC effectiveness (Abbott et. al, 2004; Klein, 2002). DeZoort et. al (2002) identify composition, authority and resources as basic inputs for AC effectiveness, but which need to be accompanied by diligence which represents one of the process factors. Bédard \& Gendron (2010) emphasize the processes employed by AC as one of key determinants of AC effectiveness. Spira (2003) concludes that without opening AC "black box" and getting actual insight in the way AC performs its activities, it is hard to assess whether $\mathrm{AC}$ is effective or not.

The issue of AC effectiveness is also of great interest for lawmakers and regulators since they have assigned significant monitoring duties to $\mathrm{AC}$. By imposing a set of requirements on companies with regard to $\mathrm{AC}$, they try to provide basis for effective work by AC. Although regulation becomes tougher in the new century, it is still mostly focused on AC composition and responsibilities, while other dimensions of effectiveness are not covered. 
In Serbia AC is a relatively new structure attracting more attention only in the last decade. In 2013 the new Auditing Law was enacted introducing for the first time the mandatory formation of AC for all PIE. In the period before 2013, only some regulated entities (e. g. banks) were obligated to have AC, and since $2011 \mathrm{AC}$ has become compulsory for public companies by the Company Law. Considering limited experience with $\mathrm{AC}$ as well as the fact that legislative pressure was the primary driver for establishing AC in companies, our study is intended to illuminate whether companies in Serbia have achieved formal compliance with best practices as well as to examine if form dominates over substance proving the premises of institutional theory in the case of AC.

\section{DEVELOPMENT OF RESEARCH QUESTIONS}

$\mathrm{AC}$ is globally considered as important actor in corporate governance, but empirical evidences do not always justify this view (Spira, 2003; Fairchild et. al, 2019). It could be also argued that it is not possible to adequately assess potential of $\mathrm{AC}$ for effective work without insight in its design and practices. In the same time, externally observable data about ACs are traditionally limited. The lack of transparency is also recognized by EC, which has specified in its action plan for improving corporate governance in EU that "listed companies should be required to include in their annual report and accounts a coherent and descriptive statement covering the key elements of their corporate governance structure and practices, which should at least include the composition and operation of the board and its committees" (EC, 2003). According to this, disclosure of $\mathrm{AC}$ composition and operation should be mandatory for listed entities. Even more, EC has stressed that AC terms of reference must be made available to the public at least once a year (EC, 2005). In their comparative study, Böhm et al. (2013) examine published $\mathrm{AC}$ charters in $6 \mathrm{EU}$ countries and find that disclosure rates in these charters for $\mathrm{AC}$ responsibilities, as well as for independent requirements and competency specification for AC members, are fairly low in most of the countries. In contrast to this study which was focused on continental Europe, transparency seems to be greater in US where AC is much longer part of corporate governance. Since 1999, the US Securities and Exchange Commission (SEC) has required that publicly traded companies make $\mathrm{AC}$ disclosures which include $\mathrm{AC}$ charter and AC report (SEC, 1999). Rezaee et. al (2003) find that 94 companies from Fortune 100 made required disclosures. By content analysis, they determine that almost all of the analysed AC charters state $\mathrm{AC}$ responsibilities, composition, size and number of meeting.

In Serbian environment, where AC does not have deep roots, the transparency issue is very relevant. More transparency should be very beneficial in terms of increasing the level of knowledge about this body and its roles, but it could also positively influences the design and work of ACs through market discipline. However, companies in Serbia traditionally are not inclined towards transparency and this could be reflected in the domain of AC too. On the other hand, the quality of financial reporting and auditing in Serbia is very questionable and companies may find it useful to disclose more information about $\mathrm{AC}$ demonstrating in that way to current and potential investors that oversight activities performed by $\mathrm{AC}$ are trustworthy and provide genuine protection of their interests. Hence, the following research question is used to examine the level of transparency regarding AC in Serbian context:

\section{$R Q$ 1: To what extent are companies in Serbia transparent about their ACs?}

The composition of $\mathrm{AC}$ is one of the main determinants of $\mathrm{AC}$ effectiveness. Without "the right people" it is not probable to build effective AC (KPMG, 2017). Although a number of characteristics could be seen as desirable for AC members to have (DeZoort et. al, 2002), two 
of them - independence and competencies are commonly treated as basic assumptions for effective work (Bédard \& Gendron, 2010). Insisting on independence is important to eliminate relationships that could influence members in a way that compromises their judgments. Independence provides basis for members to work objectively and to exercise sufficient scepticism. A number of empirical studies document that independence contributes to AC effectiveness (Abbott et. al, 2004; Ghafran \& O'Sullivan, 2013), although there are papers where no significant relationship is found (Lie et. al, 2006).

Lawmakers and regulators have imposed independence requirement with regard to AC from the very beginning, but as time passed it has become more stringent. This means making difference between non-executive and independent non-executive directors as well as increasing the proportion of independent versus non-independent members in AC. In US, SOX prescribes all members of ACs to be independent, while the new EU Auditing Directive introduced the requirement for only the majority of $\mathrm{AC}$ members to be independent. It is yet more rigorous than the earlier requirement that at least one member of the $\mathrm{AC}$ must be independent (Directive 2006/43/EC). However, practices through EU differ. Böhm at al. (2013) find in their EU comparative study that some national codes of corporate governance recommended a tougher independence rule than the Directive 2006/43/EC prescribed in that time.

Providing insight in $\mathrm{AC}$ competencies is equally important for assessing $\mathrm{AC}$ effectiveness, since without appropriate competencies it is not likely that comprehensive oversight responsibilities could be performed. Nevertheless, AC competencies have attracted broader attention only after waves of corporate scandals which makes obvious that this attribute is essential for effective AC. DeZoort et. al (2002) review AC studies at the end of XX century and find that many studies indicated that ACs did not have sufficient level of expertise in assigned oversight areas. Collier \& Zaman (2005) examine AC in 20 countries in Europe and stress that until 2003, requirement with regard to competencies was incorporated in national codes of corporate governance in only four countries. Bédard \& Gendron (2010) summarize that the results of academic studies directed to examine the relationship between $\mathrm{AC}$ competencies and $\mathrm{AC}$ effectiveness are mixed, although the overall conclusion is that $\mathrm{AC}$ competencies do not show such a strong association with AC effectiveness as independence does.

Nowadays, it is, however, globally accepted that competencies requirement must be established for AC, but practices differ in describing necessary competencies. Böhm at al. (2013) find differences in three aspects: the required level of competencies, the area to which competencies relate and the proportion of $\mathrm{AC}$ members who need to have these competencies. The most prominent requirement is yet that at least one $\mathrm{AC}$ member has financial or accounting competencies (KPMG, 2017). Nevertheless, companies could choose to determine tighter rules for their ACs than those which are prescribed in relevant regulation. In US, SOX introduced mandatory provision for public companies to disclose if they have at least one AC financial expert. This disclosure instigates companies to take more attention to the qualifications of their AC members and recent research of Center for Audit Quality (CAQ) and Audit Analytics reveals that the majority of leading US companies has accepted the practice to have more than one financial expert in their ACs (CAQ, 2016). According to this research, even $51 \%$ of S\&P 500 companies have three or more financial experts in their ACs.

The new EU Auditing Directive require that at least one $\mathrm{AC}$ member has competence in accounting and/or auditing. It is in line with the previous conclusion of EC that in the case of 
AC "some specific knowledge is deemed to be indispensable", so there is "need for particular competence in the AC" to be provided (EC, 2005, paragraph 16). It should be however noticed that the initial Proposal of Auditing Directive by EC gave much weight to technical competence of $\mathrm{AC}$ requiring that at least one member of the committee has competence in auditing and another one in auditing and/or accounting (EC, 2011, paragraph 31). This was not accepted in the final version of the Directive which keeps provision that technical competence could be satisfied with only one member with qualifications in accounting and/or auditing, but it imposes for the first time the requirement that $\mathrm{AC}$ as a whole possesses competence appropriate for the particular sector in which a company operates. Sector-specific knowledge is perceived to foster $\mathrm{AC}$ effectiveness through better understanding of key processes and relevant risks.

In Serbia, the mandatory composition of $\mathrm{AC}$ is prescribed by the Company Law. It contains a requirement for at least one independent member, which cannot be seen as a promising and strong criterion. Since Serbia aspiring to become an EU member state, it has to align its regulation with EU regulation, which means in the domain of $\mathrm{AC}$, that independence must be required for the majority of $\mathrm{AC}$ members. Consequently, companies will have to adapt to this more stringent rule. There is however uncertainty about current companies' practices with regards of independence requirements considering that they have option to go above the minimum imposed by the legislative and especially by taking into account that it means to follow the best practices. Therefore we examine in this study the extent to which companies in Serbia have already accepted the new European regulation regarding the composition of AC. We address both the question of independence and the competencies requirement. Concerning competencies, the Serbian Company Law requires that at least one AC member is a certified auditor or has appropriate expertise and experience in finance and accounting. Since form could be loosely coupled with substance, in addition to formal compliance we investigate if the composition is truly satisfactory. The following research questions are therefore posed to address the composition of ACs in Serbia:

RQ 2 (a): To what extent is the formal composition of ACs in companies in Serbia in line with requirements of the new EU Audit Directive?

RQ 2 (b): Is the composition of ACs in Serbia appropriate in substance?

Responsibilities assigned to $\mathrm{AC}$ are considered another important input factor for realizing benefits of AC. According to Wolnizer (1995), AC responsibilities traditionally pertain to three main areas: financial reporting (including internal control), auditing (external and internal) and corporate governance. There is however a trend of expanding the AC responsibilities, which nowadays commonly include oversight of risk management, but also some other issues (e.g. compliance) could be in the mandate of AC. On the other hand, some concerns have appeared regarding awareness and discharging of these responsibilities by AC members. DeZoort (1997) examines the list of AC responsibilities published in companies' proxy statements and uncovers that $\mathrm{AC}$ members "tended not to recognize the assigned responsibilities". One way to improve this situation is the use of AC charter, which clearly defines the scope of AC responsibilities and also gives $\mathrm{AC}$ authority to act. Some empirical evidence gives further support to the notion of the importance of the charter for AC effectiveness (Bédard et. al, 2004).

Since regulators have high expectations from $\mathrm{AC}$, it is common in many jurisdictions that the scope of AC responsibilities is explicitly prescribed by relevant regulation. According to the new EU Auditing Directive, AC shall: inform the board of directors of the outcome of the external audit and explain the role of external audit as well as the role of the AC in providing integrity of financial reporting; monitor the financial reporting process and submit 
recommendations and proposals to ensure its integrity; monitor the statutory audit of the annual and consolidated financial statements; monitor the effectiveness of the undertaking's internal control, internal audit and risk management systems; review and monitor independence of the external auditor and be responsible for the procedure for the selection of external auditor and recommend the external auditor for appointment. Although this scope of responsibilities is broad and challenging, it is not rare practice that national corporate governance codes and companies' boards require more responsibilities to be addressed by AC, especially in the area of compliance and corporate governance (Böhm at al., 2013). At company level it is also expected that imposed responsibilities are elaborated with more details in the related internal acts (e. g. AC charters) and with taking into account characteristics of company and industry.

Even when $\mathrm{AC}$ responsibilities are properly identified and adopted from corporate board, there is still open question whether it is only done for the purpose of regulative compliance while no actual performance of these responsibilities is expected. Institutional theory is confirmed in many AC practices. Consequently, we examine the following two research questions relating to responsibilities of ACs in Serbia:

RQ 3 (a): To what extent are responsibilities of ACs in compliance with requirements of the new EU Audit Directive?

RQ 3 (b): Do ACs discharge their responsibilities?

\section{RESEARCH METHOD}

We examine transparency and formal determinants of ACs in Serbia by content study. Similar to Böhm at al. (2013) we start from EU regulation as benchmark and then analyse content of national and company level acts dealing with $\mathrm{AC}$ to reveal the degree of compliance. Besides legislative requirements imposed by Company Law, there is national corporate governance code in Serbia issued by Serbian Chamber of Commerce and Industry which provides recommendations regarding $\mathrm{AC}$ design and responsibilities. Although these recommendations are not legally binding, the national code is influential and could play important role in encouraging companies to implement best practices even if they exceed what is required by law. Werder et. al (2005) find that adoption of national code in Germany "actually contributes to changes in corporate governance practices". We also find evidence that some Serbian companies have chosen to implement directly the national code instead of developing their own. Hence, we firstly explore the extent to which the national code recommendations promote standards set forth by EU Auditing Directive. Then, we analyse companies' acts, reports and other documents to get insight in AC standards that are finally adopted by companies. This part of analysis is important, since the level of compliance of the national code does not necessarily reflect the level of corporate compliance. It is possible that companies' practices are not homogenous. Recommendations by national code could be followed but also companies may decide not to accept them. On the other side, by prescribing minimum that must be achieved, the Company Law has left considerable scope to companies for determining standards for their ACs.

In order to perform content analysis of companies' documents, we select companies included in leading index of the Belgrade Stock Exchange - BELEX 15 as our sample. However, our final sample consists of 11 companies, since at the end of 2018 when we performed this study, only 11 companies' satisfied criteria to belong to this index. We explore public available documents which are expected to contain information about corporate governance and consequently about AC. Precisely, we study contents of following documents for each sample 
company: corporate governance code, annual report, statute, AC charter (if disclosed) and questionnaire on corporate governance practice (if disclosed). We use the latest versions of published codes, statutes and charters, while examined annual reports and questionnaires relate to 2017. Since only one company discloses its AC charter and four companies did not publish questionnaires, our study covers a total of 41 documents.

The content study leads to conclusions about formally compliance of ACs, but cannot reveal AC reality, which could differ from the form outlined in published documents. Werder et. al (2005) emphasize that form could be easily followed, but "doing so in spirit requires tougher efforts". Hence, we complement content study with survey intended to give us insight in actual functioning of ACs in Serbia. We decide to direct our survey to external auditors for the following reasons. First, they are in a good position to assess AC, since they should interact with ACs of their audit clients during performing external audit. According to their professional standards, external auditors address the quality of corporate governance, including AC, in their process of risk assessment and designing response to the assessed risks, as well as, have responsibility to communicate certain important matters to those charged with governance. On the other hand, AC has responsibility to oversee external auditing. Second, external auditors are independent what gives them advantage to be chosen as targeted population for the survey rather than $\mathrm{AC}$ members, who might tend to provide better picture of their own work. External auditors are not exposed to such bias. Besides, they do not have incentives to give "sound good" answers. We also encourage honest answers by assuring confidentiality and anonymity. Third, external auditors are competent to perform assessment of AC activities.

We used the purposive sampling technique (judgment sampling) by deliberately choosing respondents, taking into account that ACs are mainly established in PIEs which could be audited only by audit firms which satisfied certain criteria. We also limited participation in the survey to auditors which have experience with ACs, which are dominantly audit managers and partners. Responses were collected in autumn 2018/winter 2019, using a web-based Google Forms survey tool in Google Drive. The total number of respondents is 33. Demographic data show that participants worked dominantly in international or regional audit firms $(76 \%)$, while those employed by Big 4 audit firms represented $42 \%$ of all respondents. Almost all participants $(94 \%)$ were at the positions of managers or partners and had more than 5 years of auditing experience. However, majority of participants $(73 \%)$ had more than ten years of auditing experience. We also asked auditors about their experience with companies which have ACs. Significant number of auditors (76\%) had more than five years of such experience. About threequarters of all respondents are mainly engaged in auditing of entities in non-financial sectors.

Participants were informed that the objective of the survey was to obtain their experiences with audit clients, and hence there are no right or wrong answers. We used a seven-point Likert Scale (1-strongly disagree, 7-stronly agree). In order to avoid central tendency bias, we asked respondents not to follow the rule of giving neutral ("middle") option, nor to give "socially desirable" answers. Respondents had to provide answers to all questions, because it was technically impossible to return an incomplete questionnaire. We developed 12 statements, which relate to examined aspects of AC: composition and responsibilities.

\section{RESULTS AND DISCUSSION}

The results of the study are presented in four sections. Each section addresses one of previously determined research questions. For the purpose of presenting and interpreting results of the survey, most of results are given in form of tables. Each table presents a set of statements used in questionnaire to examine related research question. The percentages of respondents who 
agreed or disagreed with survey statements are shown in these tables. To calculate the percentages, we determine the respondents that chose 1, 2 or 3 on Likert scale as those who "disagree" and the respondents that chose 5,6 or 7 on the scale as those who "agree". The tables also contain descriptive statistics, precisely group means.

\subsection{Transparency of ACs}

New EU Auditing Directive emphasises importance of AC, but at the same time call for reinforcing its capacity. Concerning this, the Directive refers to the EC recommendations. These recommendations take into account a transparency issue (EC, 2005). With regard to AC transparency, EC recommends the disclosure of AC terms of reference. Thanks to this disclosure, public understanding of role and responsibilities of $\mathrm{AC}$ will be enhanced. According to KPMG AC Institute, complete terms of reference should include $\mathrm{AC}$ duties and responsibilities as well as structure, process and membership requirements (KPMG, 2017). EC also recommends for $\mathrm{AC}$ terms of reference to be made available to public at least once a year, by including its content in company's annual report. However, there are significant crossnational differences regarding the practise of AC disclosures. Some national corporate governance codes require "comply or explain" approach, meaning that non-disclosure of AC charter must be explain (e. g., UK Code, Dutch code), while codes in other countries only recommend disclosure without explaining of non-disclosure (e. g. Belgian code, Spanish code) or even do not have related recommendation (e. g. German and French codes) (Böhm et al., 2013).

We examine Serbian code and find recommendation for adoption of AC charter, but not one for its disclosure. It means that companies in Serbia do not have institutional incentive to make this kind of disclosure, which might contribute to the low level of disclosures at company level. Böhm at al. (2016) stress significant influence of recommendations, since in their sample only $35 \%$ companies from countries without disclosure recommendation publish their AC charter in comparison with $85 \%$ companies in countries with this recommendation in their national codes. Our research finds that in Serbia only one of eleven public companies listed in BELEX 15 disclosed its AC charter, which indicates unfavourable low propensity for this disclosure. Since these companies are generally under the highest pressure to be transparent, it is less likely that other companies make greater disclosures.

Even in the one particular case of disclosing AC charter, deeper analysis of its content reveals that it merely includes text of law provisions, without some industry- or company-specific information. Any benefits of the disclosure are then questionable. It is highly recommended that $\mathrm{AC}$ charter should be tailored to company needs, especially when mandatory requirements are not stringent as it is case with $\mathrm{AC}$ legislation. It should be also sufficiently detailed to give robust basis for $\mathrm{AC}$ work. Otherwise, when $\mathrm{AC}$ charter does not have these attributes, concerns are raised about $\mathrm{AC}$ substance. It could be the red flag for ceremonial nature of AC.

EC further promotes AC transparency through recommendation that certain information about AC should be included in company's annual report. Consequently, annual report should provide information about composition and operation of AC. Precisely, it should include a statement covering membership, but also a number of $\mathrm{AC}$ meetings and attendance on these meeting over the year, as well as AC main activities. This kind of disclosure provides insight in diligence of $\mathrm{AC}$ and what AC actually did in previous period. Brennan \& Kirwan (2015) underline that there is important distinction between best practice described as what AC "should do" and praxis 
relates to what AC "actually do". Therefore, this kind of disclosure is seems to be very important to reveal actual efforts of AC.

Serbian code advocates inclusion in annual report information about corporate governance structure and practices, but without particularizing items to be included. Hence, explicit recommendation about publishing AC information is not given. Table 1 shows findings from analysis of content of annual reports of companies in BELEX 15. Majority of companies ( 9 of 11) did not disclosure AC-related information. From remain two companies, only one gave complete information following EC recommendation.

Table 1. AC-related disclosures in annual reports

\begin{tabular}{|l|c|}
\hline & Number of companies \\
\hline Non-disclosures & 9 \\
\hline Disclosures & 2 \\
\hline Membership & 1 \\
\hline Number of meetings and attendance & 1 \\
\hline Main activities & \\
\hline
\end{tabular}

This finding indicates that companies do not see AC information as important enough to be communicated to investors. It could stem from their own believing that $\mathrm{AC}$ is only formed because of regulative pressure without any expectations about its value to shareholders. However, global trends reflect growing demand for AC disclosures, because of perceived effects on investor confidence (IAASB, 2013; ACC, 2015). These disclosures could be in the form of $\mathrm{AC}$ report, which would be included in annual report. SEC has already prescribed publishing of $\mathrm{AC}$ report. KPMG AC institute gives illustration of enhanced $\mathrm{AC}$ report, which is very comprehensive, but also substantially informative (KPMG, 2017).

Since most companies in BELEX 15 do not implement EC recommendations to publish AC charter and AC-related information in annual reports, we also examine other publicly available companies' documents which could content information about $\mathrm{AC}$ in order to explore if it is possible to get insight in AC composition and work elsewhere. We were also interested in information about $\mathrm{AC}$ reporting to the board, since this is also considered an aspect of transparency of the $\mathrm{AC}$ work. $\mathrm{EC}$ recommends that $\mathrm{AC}$ reports to board of director at least semi-annually.

We firstly examine corporate governance codes, due to finding that majority of companies developed their own codes ( 9 of 11), while two companies accepted to follow the national code. Although national code addresses AC through general provisions relating to all board committees as well as through special provisions deal only with $\mathrm{AC}$, there was lack of $\mathrm{AC}$ related content in most of company-level codes. Only two of these codes gave attention to AC, addressing mainly its responsibilities. On the other hand, the vast majority of companies regulated $\mathrm{AC}$ in their statues $(82 \%)$, through one to three paragraphs, but content of these paragraphs was mostly "copy paste" from Company Law. Accordingly, AC reporting to board is required, but at least once a year as prescribed by Law. Even this provision reveals no interest for adopting some advanced rules according to best practice. Similar, there is no interest for adaption of AC to specifics of company and sector where it operates.

The Belgrade Stock Exchange has launched different initiatives to improve corporate governance of listed companies. It has also addressed disclosure issue by developing corporate governance questionnaire and recommending companies to fill it out on annual basis and make 
publicly available. Most of companies (73\%) showed a readiness to accept this initiative. This questionnaire, however, does not address $\mathrm{AC}$ in a comprehensive manner, hence, it can compensate only in a low extent the lack of disclosures in companies' annual reports. It uncovers AC membership in term of names of AC members. Once again, it seems that companies do not find $\mathrm{AC}$ as essential constituent of corporate governance, since in the listing of important internal acts on corporate governance, companies did not mention AC charter. Most striking, when they were asked to specify the methods of communication between the external auditor and the company's AC, just in two cases formal communication through meeting was quoted. In other cases just auditor's statement of independence was mentioned, what is obviously not sufficient due to AC responsibility to oversight external audit.

In summary, we find that the transparency of $\mathrm{AC}$ is quite low and not in line with $\mathrm{EC}$ recommendations nor with international trends. It makes difficult for investors to get any insight in capacity of this relatively new committee in Serbia. Furthermore, it indicates that companies miss their chance to enhance investor confidence in their financial statements by demonstrating performing of effective oversight by $\mathrm{AC}$, in environment where perceptions of quality of financial reporting and auditing are doubtlessly low.

\subsection{AC composition}

Effective oversight by AC depends of characteristics of its members, among which independence and competencies are seen as critical ones. The Serbian Company Law is not however fully in accordance with new rules about AC membership prescribed by the latest EU Auditing Directive nor generally in accordance with best practices. In order to examine if companies in Serbia have some incentives to achieve higher standards in design of their ACs, we firstly analyse the Serbian corporate governance code. The Code requires that public companies establish audit committee. Since public companies could have other committees too, the Code prescribes general rules regarding composition of all committees. The rules are developed at two levels: recommendations, that companies should implement or otherwise give explanation ("comply or explain" rules) and suggestions, which are advisable practices. The comparison of provisions is given in Table 2.

Table 2. AC composition regulation in EU and Serbia

\begin{tabular}{|c|c|c|c|}
\hline & $\mathbf{E U}$ & Serbian Company Law & Serbian Code \\
\hline \multicolumn{4}{|l|}{ Independence } \\
\hline All members & - & - & $\begin{array}{l}\text { Suggestion for small } \\
\text { committees: } \sqrt{ }\end{array}$ \\
\hline Majority of members & $\sqrt{ }$ & - & Suggestion: $\sqrt{ }$ \\
\hline At least one & - & $\sqrt{ }$ & Recommendation: $\sqrt{ }$ \\
\hline Independent $\mathrm{AC}$ chief & $\sqrt{ }$ & $\sqrt{ }$ & - \\
\hline \multicolumn{4}{|l|}{ Competencies } \\
\hline $\begin{array}{l}\text { At least one member to have } \\
\text { competencies in accounting and/or } \\
\text { auditing }\end{array}$ & $\sqrt{ }$ & $\sqrt{ }$ & - \\
\hline $\begin{array}{l}\mathrm{AC} \text { as whole to have sector-relevant } \\
\text { competencies }\end{array}$ & $\sqrt{ }$ & - & - \\
\hline Professional knowledge & - & - & Recommendation: $\sqrt{ }$ \\
\hline
\end{tabular}

Concerning independence, the Code requires at least one member to be independent, but at the same time suggests majority of members to be independent, and especially in the cases of small committees (up to three), all members to be independent. Hence, the Code does not obligate, but encourages companies to accept practice that majority or even all members are independent. 
Regarding competencies, the Code only recommends that members of committees must have appropriate professional knowledge. No specifying is done for AC. We can conclude that the content of the Code is not aligned with new EU Auditing Directive which requires majority of $\mathrm{AC}$ members to be independent, and does not sufficiently address AC competencies. It could not then represent flywheel for enhancing composition of AC in companies in Serbia.

By content analysis of companies' documents previously described, we find that companies just "copy paste" the text of mandatary law provisions. Only for one company, no data about internal approach to AC composition was available. In all other cases, companies regulated AC composition through statute (nine companies) or charter (one company) in a way it was prescribed by law. We do not find even one case where independence requirement was formally in compliance with EU Auditing Directive. All companies adopted provision that "at least one" instead majority of AC members must be independent. Hence, companies do not try to regulate their ACs according to higher EU standards. Regarding competencies, it is noticeable that there is no requirement for $\mathrm{AC}$ business knowledge. However, $\mathrm{AC}$ composition could be in practice more straightforward. Since examined companies were not transparent about their ACs, our content analysis was not helpful for revealing AC composition in reality. Only for one company it was observable to have majority of members independent and for another one that had all members competent in accounting. Generally, in Serbian environment it does not seem that companies are striving to establish strong AC composition.

We then asked external auditors for their experiences relate to $\mathrm{AC}$ independence and competencies. Table 3 presents results for the statements related to these dimensions of AC membership.

Table 3. Auditors' experiences on AC composition

\begin{tabular}{|c|c|c|c|}
\hline \multirow[t]{2}{*}{ Is composition of ACs in Serbia appropriate in substance? } & \multicolumn{2}{|c|}{$\%$} & \multirow[t]{2}{*}{ Mean } \\
\hline & Disagree & Agree & \\
\hline AC has sufficient number of independent members. & 54.55 & 33.33 & 3.636 \\
\hline AC has sufficient competencies in accounting and auditing. & 54.55 & 33.33 & 3.818 \\
\hline $\begin{array}{l}\text { AC has sufficient competencies relevant to the sector in which } \\
\text { company operates. }\end{array}$ & 33.33 & 36.11 & 4.151 \\
\hline
\end{tabular}

Source: author

More than a half of auditors disagreed that $\mathrm{AC}$ had appropriate composition. This holds for independence as well as for competencies of $\mathrm{AC}$, but the group mean is however lower for independence than for competencies. It is not unexpected since the gap in AC independence is greater. "At least one independent member" is not acceptable rule anymore in EU, but also internationally, and expectations of all stakeholders are consequently higher. For external auditors, independence of AC members is significant issue and large number of them obviously did not experience it in sufficient extent. The data also indicate that there are challenges for companies in Serbia to improve competencies of their ACs. Only one third of auditors agreed that $\mathrm{AC}$ has sufficient competencies. It is very unfavourable finding, since it raises question of capacity of $\mathrm{AC}$ to discharge its oversight responsibilities. When asked about $\mathrm{AC}$ competencies relevant to the sector, auditors were a little more positive. However, $27 \%$ of auditors were neutral. It is not surprising since external auditors are not focused on this kind of competencies, hence, probably do not feel comfortable to agree or disagree with this statement. 


\subsection{AC responsibilities}

Legislative framework commonly specified a minimal scope of AC responsibilities. Beasley et. al (2009) stress that legislation has changed in the direction of expanding AC responsibilities, hence leading to sky-rocketed expectations from AC. There are however some cross-countries differences in this domain. Table 4 reveals responsibilities of AC according to EU Auditing Directive and Serbian regulation.

One of the first and undisputed responsibilities of $\mathrm{AC}$ is related to the selection of external auditor. For enhancing external auditor's independence, it is crucial that AC instead of management owns the process of selection of external auditor. Hence, it is important for quality of external audit in Serbia, that this AC responsibility is incorporated in the Company Law and the Code as well. Surprisingly, the Company Law does not include monitoring of internal control in the set of AC monitoring responsibilities. Bédard \& Gendron (2010) summarize that for regulators ultimate goal of $\mathrm{AC}$ is improving credibility of financial information, which can be achieved directly through oversight of financial reporting process, but also indirectly by oversight of internal control and external audit. This view is generally accepted and internal control system is traditionally one of the focus area of AC. However, the Code does not repeat this omission and assigns responsibility for internal control monitoring to AC. Interestingly, the Code determines the scope of AC responsibilities even broader than EU Directive, by including compliance in it. Other monitoring responsibilities are generally addressed by each analysed regulation, although the level of details in their descriptions is different. In this sense, some fine adjustments of Serbian regulation would be welcomed. Since one of companies in BELEX 15 is financial institution, we also examine the scope of AC responsibilities according to Law on Banks and find lower extent of compliance with EU Directive, since monitoring responsibilities are not prescribed for internal audit nor for independence of external auditors. However, monitoring of internal control is prescribed.

Table 4. AC responsibilities

\begin{tabular}{|l|c|c|c|}
\hline & EU & Serbian Law & Serbian Code \\
\hline Monitoring responsibilities & & & $\sqrt{ }$ \\
\hline Monitoring of financial reporting & $\sqrt{ }$ & $\sqrt{ }$ & $\sqrt{ }$ \\
\hline Monitoring of internal control & $\sqrt{ }$ & - & $\sqrt{ }$ \\
\hline Monitoring of risk management & $\sqrt{ }$ & $\sqrt{ }$ & $\sqrt{ }$ \\
\hline Monitoring of internal audit & $\sqrt{ }$ & $\sqrt{ }$ \\
\hline Monitoring of external audit performance & $\sqrt{ }$ & $\sqrt{ }$ \\
\hline Monitoring of external auditor's independence & $\sqrt{ }$ & $\sqrt{ }$ \\
\hline $\begin{array}{l}\text { Mesponsibility for selection procedure and } \\
\text { recommendation of external auditor }\end{array}$ & $\sqrt{ }$ & $\sqrt{ }$ \\
\hline Reporting to the board & $\sqrt{ }$ & \\
\hline
\end{tabular}

Source: author

Content analysis of companies' statues shows that the scope of AC responsibility is identical to the one prescribed by law. Coercive isomorphism as consequence of regulative-type pressure has its advantages, but also indicates lack of interest of companies to use space left by law to adapt AC best to their needs. It is noticeable that no company, except one bank, included monitoring of the internal control as AC responsibility. In the case of only one company, which made its AC charter public available, we find that also "copy paste" approach was used, although charter should be more detailed with decomposition of broad term responsibilities in concreted duties. However, two companies in their codes of corporate governance gave mandate to $\mathrm{AC}$ for monitoring of internal control and even monitoring of compliance. It could 
be confusing for $\mathrm{AC}$ members if their responsibilities are not determined in the same way. To summarize, although companies in Serbia have high level of formal compliance with EU Auditing Directive with regard to AC responsibilities, it could be improved, primarily by including monitoring of internal control for enterprises, while for banks more adjustments should be done.

In addition, we examine how effective are ACs in discharging their monitoring responsibilities, Table 5 presents results based on auditors' experience. It is of the great concern that majority of external auditors disagreed that AC substantially discharged any of listed responsibilities. Although the highest mean value, revealed through these statements about responsibilities, is related to the monitoring of the financial reporting process, it is still insufficiently to indicate that $\mathrm{AC}$ presents strong structure in ensuring quality of financial statements. Regardless of the lack of assigned responsibility for monitoring of internal control by Company Law and even companies' acts, results are similar for this responsibility as for the other. Less than a third respondents agreed that substantive monitoring is performed. In the area of risk management and internal audit the results are most concerning. This could be potentially explained by the fact that these areas are also relatively new and not well developed in Serbia.

Table 5. AC discharging of its monitoring responsibilities

\begin{tabular}{|c|c|c|c|}
\hline \multirow{2}{*}{ Do ACs substantially discharge their responsibilities? } & \multicolumn{2}{|c|}{$\%$} & \multirow{2}{*}{ Mean } \\
\hline & Disagree & Agree & \\
\hline AC substantially monitor financial reporting process. & 54.55 & 33.33 & 3.455 \\
\hline AC substantially monitor internal control system. & 60.61 & 30.30 & 3.364 \\
\hline AC substantially monitor risk management system. & 63.64 & 24.24 & 2.727 \\
\hline AC substantially monitor internal audit. & 63.64 & 27.27 & 3.212 \\
\hline AC substantially monitor external audit. & 57.58 & 30.30 & 3.273 \\
\hline AC substantially review and monitor the independence of external auditor. & 57.58 & 30.30 & 3.455 \\
\hline $\begin{array}{l}\text { AC substantially review and monitor the provision of non-audit services by } \\
\text { external auditor. }\end{array}$ & 60.61 & 24.24 & 3.273 \\
\hline
\end{tabular}

Source: author

One of the most important objectives of ACs is improving external audit quality, what is accomplished through strengthening auditor independence as well as through effective monitoring of auditor performance. Since quality of the external auditing is everlasting issue, contribution of AC in this area is of the great importance. However, results of our survey reveal that actual engagement of ACs in Serbia in the monitoring of external audit is unsatisfactory. More than half of auditors did not experience monitoring in substance. Unfortunately, this relates to all three statements regarding monitoring of external auditing. Concerning independence and non-audit services, one potential explanation for the lack of substantial monitoring could be found in a comfort that $\mathrm{AC}$ gets with obligation of external auditors to provide statements on independence as well as to inform AC about non-audit services. It seems that ACs do not perceive necessity to challenge these statements.

In Table 6 we present results for the statements regarding the selection of external auditors. Formally, AC has mandate for the procedure and recommendation for the selection of the external auditor, but performing of this mandate in practice appears to be questionable. Only about a quarter of auditors agreed that AC played primary role in the selection of external auditors. Furthermore, two third of auditors disagreed with this statement. The group mean is just 2.818. On the other hand, for the statement that management plays primary role in the selection of external auditors, the group mean is 5.061, what uncovers that management is much more influential than AC. Almost $70 \%$ of external auditors agreed with this statement. 
Table 6. Selection of external auditor

\begin{tabular}{|l|c|c|c|}
\hline \multirow{2}{*}{$\begin{array}{l}\text { Do ACs substantially discharge their responsibility with respect to } \\
\text { selection of external auditor? }\end{array}$} & \multicolumn{2}{|c|}{ Mean } \\
\cline { 2 - 3 } & Disagree & Agree & \\
\hline AC has primary role in the selection of the external auditor. & 66.67 & 24.24 & 2.818 \\
\hline Management has primary role in the selection of the external auditor. & 18.18 & 69.70 & 5.061 \\
\hline
\end{tabular}

Source: author

Once again, it seems that in Serbian environment AC substance is not achieved. Results are consistent with assumptions of institutional instead of agency theory. It is however interesting that even developed countries with long AC tradition face this problem of management domination over AC with respect to the selection of external auditors. Cohen et al. (2010) conclude that in the post-SOX era in USA, ACs have become more active and powerful, but in some instances further play a symbolic role, what is particularly in the case of decisions about hiring auditors. Grenier et. al (2012) discuss that if AC does not effectively monitor external auditors' performance than AC is also not able to play important role in the selection of auditors. These responsibilities are related, because AC needs to have arguments to thwart management influence. The empirical evidence provided in this study indicates deficiencies in discharging both responsibilities by ACs in Serbia.

\section{CONCLUSIONS}

There are numerous studies on AC in developed countries, but relatively little is known about importance of this corporate governance structure in emerging countries. Since these countries commonly do not have market-driven incentives for developing advanced structures and practices, legislative pressure is used to enforce their implementation. In such situations, the likelihood that formal structures will have ceremonial role increases. Due to the fact that $\mathrm{AC}$ is entrusted with a number of monitoring responsibilities on behalf of the board of directors, it is of the great concern to be uncovered its actual contribution.

We find that companies in Serbia are faced with serious challenges regarding their ACs. The first challenge relates to the low level of transparency, which is not in line with the recommendations of EC and the global trends that promote increasing disclosures. The vast majority of companies listed in BELEX do not disclose any information about AC in its annual statements nor publish AC terms of references. Although not mandatory, these disclosures could be very beneficial for companies and society as whole, hence, all relevant parties (e. g. policymakers, audit profession) should make efforts to raise awareness of the importance of AC transparency.

Second challenge is imposed by inappropriate formal regulation of AC in Serbia. The Serbian Company Law should be amended in a manner to comply with the new EU Auditing Directive. However, in the meantime, companies are not hindered by the Law to accept advanced standards for their ACs. Nevertheless, our content analysis does not find any company's regulation that is fully in accordance with the Directive. Furthermore, we do not find any original content in a company's regulation, but only replication of the text from the Law. These findings raise concern that ACs in Serbia play only symbolic role. The survey of experienced external auditors confirm this concern. It appears that Serbian companies do not recognize potential benefits they would have if AC had worked properly. The lack of awareness is a sever challenge that must be overcome in order to achieve desired outcomes from AC. We hope that the results of this study will serve as a wake-up call for all parts interested in the potential contribution of $\mathrm{AC}$ to be more active in promoting, supporting and strengthening its role. It is 
also important to promote best practices for ACs, including requirement for AC to regularly assess its own performance.

\section{REFERENCES}

Abbott, L., Parker, S., \& Peters, G. (2004). Audit Committee Characteristics and Restatements. Auditing: A Journal of Practice \& Theory, 23(1), pp. 69-87.

Audit Committee Collaboration (ACC). (2013). Enhancing the Audit Committee Report: A Call to Action. Retrieved January 15, 2019, from: https://www.thecaq.org/enhancing-auditcommittee-report-call-action

Beasley, M., Carcello, J., Hermanson D., \& Neal, T. (2009). The audit committee oversight process. Contemporary Accounting Research, 26(1), 65-122.

Beattie, V., Fearnley, S., \& Hines, T. (2014). Boundary spanning and gatekeeping roles of UK audit committees. Accounting and Business Research, 44(3), 315-343.

Bédard, J. \& Gendron, Y. (2010). Strengthening the Financial Reporting System: Can Audit Committees Deliver?, International Journal of Auditing, 14, 174-210.

Bédard, J., Chtourou, S., Courteau, L. (2004). The Effect of Audit Committee Expertise, Independence, and Activity on Aggressive Earnings Management. Auditing: A Journal of Practice \& Theory, 23(2), 13-35.

Böhm, F., Bollen, L. \& Hassink, H. (2016). Audit Committee Charter Scope: Determinants and Effects on Audit Committee Effort. International Journal of Auditing, 20, 119-132.

Böhm, F., Bollen, L., \& Hassink, H. (2013). Spotlight on the Design of European Audit Committees: A Comparative Descriptive Study. International Journal of Auditing, 17, 138-161.

Brennan, N. \& Kirwan, C. (2015). Audit committees: practices, practitioners and praxis of governance", Accounting, Auditing \& Accountability Journal, 28(4), 466-493.

Center for Audit Quality. (2016). The Audit Committee of the Future, CAQ Insights, 1(1).

Cohen, J., Krishnamoorthy, G. \& Wright A. (2010). Corporate governance in the post SarbanesOxley Era: Auditor experiences. Contemporary Accounting Research, 27(3), 751-786.

Collier, P. \& Zaman, M. (2005). Convergence in European Corporate Governance: The Audit Committee Concept. Corporate Governance: An International Review, 13(6), 753-768.

DeZoort, F., Hermanson, D., Archambeault, D. \& Reed, S. (2002). Audit Committee Effectiveness: A Synthesis of the Empirical Audit Committee Literature, Journal of Accounting Literature, 21, 38-75.

DeZoort, F. (1997). An Investigation of Audit Committees' Oversight Responsibilities, ABACUS, 33(2), 208-227.

European Commission. (2011). Proposal for a Regulation of the European Parliament and of the Council: on specific requirements regarding statutory audit of public interest entities. Brussels.

European Commission. (2005). Commission Recommendation on the Role of Non-Executive or Supervisory Directors of Listed Companies and on the Committees of the (Supervisory) Board. Brussels.

European Commission. (2003). Modernizing Company Law and Enhancing Corporate Governance in the European Union - A Plan to Move Forward. Brussels.

European Union. (2014). Directive 2014/56/EU of the European Parliament and of the Council of 16 April 2014 Amending Directive 2006/43/EC on Statutory Audits of Annual Accounts and Consolidated Accounts. Brussels.

European Union. (2006). Directive 2006/43/EC of the European Parliament and of the Council of 17 May 2006. of statutory audits of annual accounts amending Council Directives 78/660/EEC and 83/349/EEC and repealing Council Directive 84/253/EEC. Brussels. 
Fairchild, R., Gwilliam, D. \& Marnet, O. (2019). Audit within the corporate governance paradigm: a cornerstone built on shifting sand? British Journal of Management, 30(1), 90-105.

Ghafran, C. \& O'Sullivan, N. (2013). The Governance Role of Audit Committees. International Journal of Management Reviews, 15, 381-407.

Grenier, J., Ballou, B. \& Philip, S. (2012). Enhancing Perceived and Actual Audit Committee Effectiveness through Financial Expert Certification. Current Issues in Auditing 6(2), A15-A25.

International Auditing and Assurance Standards Board (IAASB). (2013). A Framework for Audit Quality (A consultation paper). International Federation of Accountants (IFAC).

Kalbers, P. \& Fogarty, T. (1998). Organizational and Economic Explanations of Audit Committee Oversight. Journal of Management Issues, 10(2), 129-150.

Klein, A. (2002). Audit committee, board of director characteristics, and earnings management. Journal of Accounting and Economics, 33(3), 375-400

Köhler, A. (2005). Audit Committees in Germany - Theoretical Reasoning and Empirical Evidence. Schmalenbach Business Review, 57, 229-252.

KPMG Audit Committee Institute. (2017). Audit Committee Handbook. KPMG International Cooperative.

Levitt, A. (2000). Remarks before the conference on the rise and effectiveness of new corporate governance standards. Federal Reserve Bank of New York, December 12. Lin, J., Li, J. \& Yang, J. (2006). The effect of audit committee performance on earnings quality. Managerial Auditing Journal, 21(9), 921-933.

Mautz, R. K. \& Neumann F. L. (1970). Corporate Audit Committees. Illinois: University of Illinois, Bureau of Economic and Business Research.

Mautz, R. K. \& Neumann, F. L. (1977). Corporate Audit Committees: Policies and Practices. Cleveland: Ernst \& Whinney.

Paris, G., Savage, G. \& Seitz, R. (2004). Report of the Investigation of the Special Committee of the Board of Directors of Hollinger International Inc. Greenwich, CT: Richard C. Breeden \& Co.

Porter, B. A. \& Gendall, P. J. (1993). An International Comparison of the Development and Role of Audit Committees in the Private Corporate Sector. Discussion Paper Series, Massey University, Palmerston North, NZ.

Rezaee, Z., Olibe, K. \& Minmier, G. (2003). Improving corporate governance: the role of audit committee disclosures, Managerial Auditing Journal, 18(6/7), 530-537.

SEC. (1999). Final rule: Audit Committee Disclosure. Release No. 34-42266. Securities and Exchange Commission. Washington.

Sikka, P. (2009). Financial crisis and the silence of auditors. Accounting, Organizations and Society. 34(6/7), 868-873.

Spira, L. (2003). Audit Committees: Begging the Question, Corporate Governance. 11(3), 180188.

Tricker, R. I. (1978). The Independent Director: A Study of the Non-executive Director and the Audit Committee. Tolley Publishing Company Ltd, London.

Turley, S \& Zaman, M. (2004). The Corporate Governance Effects of Audit Committees. Journal of Management and Governance, 8, 305-332.

Vanasco, R. (1994). The Audit Committee: An International Perspective. Managerial Auditing Journal, 9(8), 18-42.

Werder, A., Talaulicar, T. \& Kolat, G. (2005). Compliance with the German Corporate Governance Code: an empirical analysis of the compliance statements by German listed companies. Corporate Governance: An International Review. 13(2), 178-187.

Wolnizer, W. (1995). Are Audit Committees Red Herrings? Abacus, 31(1), 45-66. 